\title{
In-Hospital Mortality after Balloon Aortic Valvuloplasty
}

\author{
Shiv Raj ${ }^{1 *}$, Ram Balasubramanian ${ }^{2}$, Robert Frankel ${ }^{3}$, Gerald Hollander ${ }^{3}$ and Jacob Shani ${ }^{3}$ \\ ${ }^{1}$ Department of Medicine, Maimonides Medical Center, USA
}

${ }^{2}$ Danville Heart and Vascular Center, Duke Health Affiliate, USA

${ }^{3}$ Maimonides Medical Center, Heart \& Vascular Institute, USA

Submission: April 04, 2017; Published: May 30, 2017

*Corresponding author: Shiv Raj, Department of Medicine, Maimonides Medical Center, 4802 10th Avenue, Brooklyn, NY 11219, USA,

Tel: +1 732829 0459; Email: shivgraj@gmail.com

\begin{abstract}
Background: Surgical aortic valve replacement (SAVR) and transcatheter aortic valve replacement (TAVR) have been shown to improve symptoms and overall survival in patients with severe, symptomatic aortic stenosis (AS). However, there still remains a group of patients not considered as appropriate candidates due to comorbid conditions and/or hemodynamic instability. The purpose of this study is to evaluate the in-hospital mortality of this high risk group undergoing BAV.
\end{abstract}

Methods: An institutional BAV registry was created to compare baseline clinical characteristics with treatment outcomes and its associations with in-hospital mortality. Univariate analyses for continuous variables were performed with analysis of variance and Mann Whitney tests. Univariate analyses for categorical variables were preformed with Pearson chi square and Fischer's exact test. Multivariate logistic regression analyses were performed with variables statistically significant within the in-hospital mortality group.

Results: This retrospective, single-center cohort included 68 patients who underwent BAV with 10 patients (15\%) having post-procedural in-hospital mortality. The surviving patients had an average body mass index (BMI) of 25.8 (range 20.9-36.7) as opposed to the in-hospital mortality group with a BMI of 20.2 (range 16.8-22.9). The in-hospital mortality group has significantly higher rates of acute kidney injury $(1.3 \pm 0.5$ vs $2.3 \pm 2, \mathrm{P}<0.003)$ prior to procedure, significantly elevated pulmonary artery pressures $(45 \pm 10 \mathrm{vs} 28 \pm 12 \mathrm{mmHg}, \mathrm{P}<0.01)$, and elevated left ventricular end diastolic pressures $(28 \pm 11$ vs $23 \pm 23 \mathrm{mmHg}, \mathrm{P}<0.047)$ when compared to the survival group.

Conclusion: Developments in technique with the use vascular closure devices, catheters with smaller sheath sizes, and the use of rapid ventricular pacing has lead to improved outcomes when compared to prior registries. Limited information regarding bridging patients to SAVR/ TAVR with BAV currently exists and more information needs to be obtained, especially as individuals are living longer and aortic stenosis being inevitable.

Keywords: Aortic stenosis; In-hospital mortality; Balloon aortic valvuloplasty

Abbreviations: SAVR: Surgical Aortic Valve Replacement; TAVR: Transcatheter Aortic Valve Replacement; AS: Aortic Stenosis; BAV: Balloon Aortic Valvuloplasty

\section{Introduction}

With increasing life expectancies, the burden of aortic valve disease continues to be a major contributor to morbidity and mortality, affecting millions of elderly people [1,2]. Aortic stenosis (AS) begins with a long asymptomatic period [3]. Once symptomatic, survival becomes poor unless the outflow obstruction is relieved [4-6]. Retrospective studies have shown that if the patient experiences symptoms of angina the medial survival is 5 years, syncope 3 years, and heart failure 2 years
$[4,7,8]$. Surgical and Transcatheter aortic valve replacement (TAVR) have been shown to improve symptoms and overall survival in patients with severe, symptomatic AS $[9,10]$. However, there still remains a group of patients that are not appropriate candidates for either procedure due to severe comorbidities and/or hemodynamic instability $[11,12]$.

In 1986, Dr. Alain Cribier [13] introduced percutaneous balloon aortic valvuloplasty (BAV) as an alternative to surgical 
valve. Even though BAV had been shown to have an immediate impact on hemodynamic parameters and clinical symptoms, procedural complications are common and long term outcomes remain poor. Current AHA/ACC guidelines state that BAV might be reasonable as a bridge to surgery in hemodynamically unstable adult patients with AS at high risk for aortic valve replacement (AVR) as well as for palliation in adult patients with AS in whom AVR cannot be performed because of serious comorbid conditions (both Class IIb indications with Level of Evidence: C), but not recommended as an alternative to AVR in adult patients with AS.

Since the advent of this procedure, there have been many developments, most significantly being the reduction in vascular complications associated with BAV [14]. It is now an increasingly common situation where patients who were initially deemed inoperable and/or unstable for SAVR/TAVR subsequently underwent $B A V$ and were later bridged to these more definitive interventions. In this background, we wanted to assess the inhospital mortality of patients who underwent BAV at the Heart and Vascular Center at Maimonides Medical Center, Brooklyn, NY where it has been performed since 1987. We sought to create an institutional balloon aortic valvuloplasty registry in order to compare baseline clinical characteristics with treatment outcomes and its associations with in-hospital mortality.

\section{Methods}

All patients who underwent BAV at the Maimonides Medical Center Heart \& Vascular Center from January 1994 to December 2013 were screened for enrollment in this singlecenter retrospective cohort study. Patients with severe aortic regurgitation, bicuspid aortic valve, or the presence of aortic vegetation were not eligible. Of note, procedures performed before 1994 and dating back as far as 1987 at this institution could not be retrieved. All patients were evaluated for surgical valve replacement by cardiothoracic surgery and were deemed unsuitable or high risk. All BAV procedures were performed mostly by a single operator. This study involving chart review and survival analysis was approved by the hospital institutional review board.

\section{Data collection}

Clinical and procedural notes were retrospectively reviewed to obtain detailed baseline clinical characteristics, echocardiographic characteristics, and hemodynamic data by cardiac catheterization. All echocardiograms were reviewed and reported by experienced cardiologists. BAV procedural report was generated by the interventional cardiologist who performed the procedure. The echocardiographic, hemodynamic and procedural data were collected from reports stored in Apollo electronic medical record database system. In-hospital mortality data was obtained by chart review from the All-scripts electronic medical record database system, paper charts from medical archives and supplemented with the New York State Department of Health Death Registry. Extensive baseline procedural and post-procedural data were tabulated in all 68 patients.

\section{Procedure}

All patients initially underwent a routine right and left heart catheterization by a femoral approach with measurements of baseline hemodynamics including right atrial, right ventricular, pulmonary artery, pulmonary capillary wedge, left ventricular and aortic pressures. Cardiac output and cardiac index were estimated by Fick's method. The aortic valve area was calculated by using the Gorlin's equation.

Using a sterile technique, BAV's were performed via the retrograde femoral approach under local anesthesia through a 12 french introducer sheath. Unfractionated heparin was given at the start of the procedure to achieve an activated clotting time of 250 to 300 seconds.

A straight-tipped wire was used to pass through the aortic valve and into the left ventricle followed by a diagnostic catheter in order to measure peak and mean systolic valve gradients. Afterwards, an extra-stiff guide wire with a soft tip was placed into the left ventricle while the diagnostic catheters and sheaths were retracted and the uninflated balloon was positioned across the valve. Rapid ventricular pacing was initiated if present during balloon inflation. Generally, no more than two inflations with the same balloon size was used prior to upsizing if warranted. After dilating the aortic valve orifice, diagnostic catheters were repositioned to measure post dilation hemodynamics. Hemostasis was obtained using manual compression and/or vascular closure devices.

\section{Statistical analysis}

Descriptive statistics of mean and standard deviation were calculated for the continuous variables and percentage and frequency for the categorical variables. Univariate analyses for continuous variables were performed with analysis of variance (ANOVA) for the normally distributed variables and the Mann Whitney test for skewed variables. Univariate analyses for categorical variables were performed with either the Pearson chi square test or when a cell size was less than 5 with the Fisher's exact test. All mortality comparisons statistically significant in the univariate analyses were included in multivariate logistic regression analyses. Due to the small sample size, separate multivariate models were conducted for each classification. IBM SPSS Statistics Version 23 was used for all analyses. All p-values were two-sided.

\section{Results}

This retrospective, single-center cohort included 68 patients who underwent BAV for calcific aortic stenosis from January 1994 to December 2013. Each procedure was performed using a retrograde percutaneous femoral approach. Among the 68 patients, 10 patients $(15 \%)$ had post-procedural in-hospital mortality. The mean age of the cohort was $85 \pm 8$ years and was 


\section{Journal of Cardiology \& Cardiovascular Therapy}

similar between the survival and in-hospital mortality group (Table 1). Of the 58 patients that survived, 34 (59\%) of patients were female. Of the 10 patients with in-hospital mortality, 7 $(70 \%)$ were female. None of the demographic variables (Table 1) statistically differed between the mortality groups. The lab values of blood urea nitrogen $(35 \pm 19$ vs $59 \pm 30, \mathrm{P}<0.005)$ and creatinine $(1.3 \pm 0.5$ vs $2.3 \pm 2, \mathrm{P}<0.003)$ both had statistically significant greater mean values for those with mortality as compared to those without mortality. Comorbidities were compared between both groups (Table 2). Of the 58 surviving patients, 30 (52\%) had coronary artery disease (CAD), 33 (57\%) had hypertension (HTN), 23 (40\%) had hyperlipidemia, and $35(60 \%)$ had congestive heart failure. Of the 10 patients with in-hospital mortality, 5 (50\%) had CAD, 4 (40\%) had HTN, and $6(60 \%)$ had congestive heart failure. None of the variables statistically differed between the mortality groups.

Table 1: Demographics and Lab Values at Baseline.

\begin{tabular}{|c|c|c|c|}
\hline Variable & $\begin{array}{c}\text { No Mortality } \\
\text { M (SD) or Percent (Frequency) }\end{array}$ & $\begin{array}{c}\text { Yes Mortality } \\
\text { M (SD) or Percent (Frequency) }\end{array}$ & p-value \\
\hline Age (years) & $85.1(9.47)$ & $85.5(7.74)$ & 0.90 \\
\hline Gender & $41.4 \%(24 / 58)$ & $30.0 \%(3 / 10)$ & 0.73 \\
Men & $58.6 \%(34 / 58)$ & $70.0 \%(7 / 10)$ & 0.58 \\
\hline Bomen & $5.8 \%(3 / 52)$ & $14.3 \%(1 / 7)$ & $57.1 \%(4 / 7)$ \\
Underweight (<18.5) & $50.0 \%(26 / 52)$ & $0.0 \%(0 / 7)$ & 0.86 \\
Normal (18.5-24.9) & $28.8 \%(15 / 52)$ & $125.9(22.24)$ & 0.89 \\
\hline Overweight (25.0-29.9) & $15.4 \%(8 / 52)$ & $64.8(16.77)$ & 0.005 \\
\hline Systolic Blood Pressure (mm Hg) & $124.3(23.65)$ & $59.9(30.11)$ & 0.003 \\
\hline Diastolic Blood Pressure (mm Hg) & $64.0(13.73)$ & $2.3(1.94)$ & 0.26 \\
\hline Blood Urea Nitrogen (mg/dL) & $35.3(19.05)$ & $90.0 \%(9 / 10)$ & 0.18 \\
\hline Creatinine (mg/dL) & $1.3(0.52)$ & $100.0 \%(8 / 8)$ & \\
\hline Hemoglobin (abnormal) & $67.3 \%(35 / 52)$ & $75.5 \%(37 / 49)$ & \\
\hline Hematocrit (abnormal) & & & \\
\hline
\end{tabular}

Note: M: Mean; SD: Standard Deviation; sample sizes vary from n=68 reported for age, Mann Whitney test performed for age

Table 2: Shows comparisons for past medical history variables. None of the variables statistically differed between the mortality groups.

\begin{tabular}{|c|c|c|c|}
\hline Variable & $\begin{array}{c}\text { No Mortality Percent } \\
\text { (Frequency) }\end{array}$ & $\begin{array}{c}\text { Yes Mortality Percent } \\
\text { (Frequency) }\end{array}$ & p-value \\
\hline Coronary artery disease & $51.7 \%(30 / 58)$ & $50.0 \%(5 / 10)$ & 0.92 \\
\hline Hypertension & $56.9 \%(33 / 58)$ & $40.0 \%(4 / 6)$ & 0.49 \\
\hline Hyperlipidemia & $39.7 \%(23 / 58)$ & $30.0 \%(3 / 10)$ & 0.73 \\
\hline Diabetes mellitus & $27.6 \%(16 / 58)$ & $0.0 \%(0 / 10)$ & 0.06 \\
\hline Congestive heart failure & $60.3 \%(35 / 58)$ & $60.0 \%(6 / 10)$ & 0.58 \\
\hline Peripheral arterial disease & $12.1 \%(7 / 58)$ & $0.0 \%(0 / 10)$ & 1.00 \\
\hline Cerebrovascular accident & $8.6 \%(5 / 58)$ & $0.0 \%(0 / 10)$ & 0.27 \\
\hline Atrial fibrillation & $1.7 \%(1 / 58)$ & $10.0 \%(1 / 10)$ & 0.21 \\
\hline Chronic kidney disease & $6.9 \%(4 / 58)$ & $20.0 \%(2 / 10)$ & 0.10 \\
\hline Anemia & $3.4 \%(2 / 58)$ & $20.0 \%(2 / 10)$ & 0.48 \\
\hline Chronic lung disease & $5.2 \%(3 / 58)$ & $10.0 \%(1 / 10)$ & 0.39 \\
\hline Coronary artery bypass grafting & $17.2 \%(10 / 58)$ & $30.0 \%(3 / 10)$ & 0.66 \\
\hline Percutaneous coronary & $15.5 \%(9 / 58)$ & $20.0 \%(2 / 10)$ & \\
\hline intervention & & & \\
\hline
\end{tabular}

Echocardiography characteristics were compared between the groups (Table 3). With regard to baseline measurements prior to BAV, the mean left ventricular ejection fraction (LVEF) in patients that survived was $37.4 \% \pm 15$ vs $53 \% \pm 18$ in the inhospital mortality group. The mean aortic valve area was similar between both groups at $0.6 \mathrm{~cm}^{2}$. Estimated systolic pulmonary artery pressure had a statistically significant greater mean value for those with mortality $(68 \pm 28 \mathrm{mmHg})$ as compared to those without mortality $(49 \pm 13 \mathrm{mmHg})$. With regard to postBAV echocardiography, the mean LVEF in the surviving patients increased to $44 \% \pm 14$ as opposed to the in-hospital mortality group with a decrease to $45 \% \pm 32$. The increase in mean aortic valve area was similar between both groups at $0.9 \mathrm{~cm}^{2}$. Those without mortality had a statistically significant greater 


\section{Journal of Cardiology \& Cardiovascular Therapy}

percentage than those with mortality for aortic insufficiency (57\% vs 20\%, respectively). Also, Mann Whitney comparisons for inflations with available data from a smaller subset of 39 patients found that those without mortality $(\mathrm{M}=2.9, \mathrm{SD}=4.28$,

Table 3: Echocardiography Findings.

\begin{tabular}{|c|c|c|c|}
\hline \multicolumn{1}{|c|}{ Variable } & $\begin{array}{c}\text { No Mortality M (SD) or Percent } \\
\text { (Frequency) }\end{array}$ & $\begin{array}{c}\text { Yes Mortality M (SD) or Percent } \\
\text { (Frequency) }\end{array}$ & p-value \\
\hline $\begin{array}{c}\text { Left atrial internal diameter in } \\
\text { end-systole }\end{array}$ & $4.8(0.89)$ & $5.3(0.38)$ & 0.32 \\
\hline Left ventricular ejection fraction & $37.4(14.82)$ & $53.3(17.56)$ & 0.09 \\
\hline Aortic valve area & $0.6(0.15)$ & $40.0 \%(4 / 10)$ & 0.80 \\
\hline Aortic insufficiency & $53.4 \%(31 / 58)$ & $68.3(28.19)$ & 0.03 \\
\hline $\begin{array}{c}\text { Estimated systolic pulmonary } \\
\text { artery pressure (mmHg) }\end{array}$ & $48.7(12.75)$ & $5.6(0.70)$ & 0.06 \\
\hline \multicolumn{2}{|c|}{ Post-Procedure } & $46.7(32.15)$ & 0.91 \\
\hline $\begin{array}{c}\text { Left atrial internal diameter in } \\
\text { end-systole }\end{array}$ & $4.5(0.88)$ & $0.9(0.34)$ & 0.90 \\
\hline Left ventricular ejection fraction & $44.2(14.74)$ & $20.0 \%(2 / 10)$ & 0.04 \\
\hline Aortic valve area & $0.9(0.24)$ & $60.0(--)$ & 0.48 \\
\hline Aortic insufficiency & $56.9 \%(33 / 58)$ & & \\
\hline $\begin{array}{c}\text { Estimated systolic pulmonary } \\
\text { artery pressure (mmHg) }\end{array}$ & $46.2(18.22)$ & & \\
\hline
\end{tabular}

Note: M: Mean; SD: Standard Deviation, Post-procedure estimated systolic pulmonary artery pressure only had $n=12$ for no mortality and $n=1$ for yes mortality. No SD is available for $n=1$.

BAV resulted in mean trans-aortic gradient from $41.4 \pm 14.8$ to $20.6 \pm 11.5 \mathrm{mmHg}$, an increase in mean aortic valve area from $0.48 \pm 0.16$ to $0.91 \pm 0.24 \mathrm{~cm} 2$, an increase in mean cardiac output from $3.1 \pm 1.0 \mathrm{~L} / \mathrm{min}$ to $3.5 \pm 1.0 \mathrm{~L} / \mathrm{min}$, a decrease in mean left ventricular systolic pressure from $167.4 \pm 33.5$ to $156.3 \pm 29.2 \mathrm{mmHg}$, a decrease in mean pulmonary capillary wedge pressure from $26.2 \pm 12.3$ to $22.8 \pm 11.0 \mathrm{mmHg}$ and a decrease in mean pulmonary artery pressure from $30.9 \pm 13.6$ to $29.6 \pm 12.6 \mathrm{mmHg}$. Hemodynamic measurements prior to BAV were compared between those without mortality vs inpatient $\mathrm{n}=35)$ had a statistically significant association $(\mathrm{p}=0.02)$ of increased number of inflations as compared to those with mortality $(M=1.0, S D=0.00, n=4)$.

Table 4: Pre-Balloon Aortic Valvuloplasty.

\begin{tabular}{|c|c|c|c|}
\hline Variable & No Mortality M (SD) & Yes Mortality M (SD) & p-value \\
\hline Systolic pulmonary arterial pressure (mmHg) & $49.6(19.68)$ & $68.0(11.27)$ & 0.02 \\
\hline Diastolic pulmonary arterial pressure $(\mathrm{mmHg})$ & $19.0(10.91)$ & $30.1(7.20)$ & 0.01 \\
\hline Mean pulmonary arterial pressure $(\mathrm{mmHg})$ & $29.2(13.35)$ & $42.8(8.13)$ & 0.01 \\
\hline Pulmonary capillary wedge pressure (mmHg) & $24.8(12.40)$ & 35.7 (5.99) & 0.03 \\
\hline Cardiac index $\left(\mathrm{L} / \mathrm{min} / \mathrm{m}^{2}\right)$ & $1.9(0.57)$ & $1.7(0.42)$ & 0.54 \\
\hline Systolic aortic blood pressure (mmHg) & $127.7(26.37)$ & $103.8(23.10)$ & 0.01 \\
\hline Diastolic aortic blood pressure (mmHg) & $57.8(12.71)$ & $49.1(10.28)$ & 0.06 \\
\hline Left ventricular diastolic pressure $(\mathrm{mmHg})$ & $20.6(10.67)$ & $26.9(10.41)$ & 0.10 \\
\hline Mean gradient & $41.9(15.23)$ & $38.2(11.88)$ & 0.52 \\
\hline
\end{tabular}

Note: M: Mean, SD: Standard Deviation

mortality group (Table 4). There were statistically significant greater mean values for those with mortality as compared to those without mortality for systolic pulmonary arterial pressure ( $86 \pm 11$ vs $50 \pm 20 \mathrm{mmHg}, \mathrm{P}<0.02$ ), diastolic pulmonary arterial pressure $(30 \pm 7$ vs $19 \pm 11 \mathrm{mmHg}, \mathrm{P}<0.01)$, mean pulmonary arterial pressure $(43 \pm 8 \mathrm{vs} 29 \pm 13 \mathrm{mmHg}, \mathrm{p}<0.01)$, and pulmonary capillary wedge pressure ( $36 \pm 6$ vs $25 \pm 12 \mathrm{mmHg}, \mathrm{p}<0.03$ ). There was a statistically significant greater mean value for those without mortality as compared to those with mortality for systolic aortic blood pressure (128 \pm 26 vs $104 \pm 23 \mathrm{mmHg}$ ). 


\section{Journal of Cardiology \& Cardiovascular Therapy}

Table 5: Post-Balloon Aortic Valvuloplasty.

\begin{tabular}{|c|c|c|c|}
\hline Variable & No Mortality M (SD) & Yes Mortality M (SD) & p-value \\
\hline Mean pulmonary arterial pressure $(\mathrm{mmHg})$ & $28.0(11.85)$ & $44.59(9.74)$ & 0.01 \\
\hline Pulmonary capillary wedge pressure (mmHg) & $22.1(11.04)$ & $30.7(7.37)$ & 0.20 \\
\hline Cardiac index $\left(\mathrm{L} / \mathrm{min} / \mathrm{m}^{2}\right)$ & $2.2(0.55)$ & $2.0(0.54)$ & 0.49 \\
\hline Systolic aortic blood pressure (mmHg) & $144.4(23.83)$ & $113.56(27.81)$ & 0.001 \\
\hline Diastolic aortic blood pressure (mmHg) & $62.9(14.23)$ & $49.9(8.30)$ & 0.01 \\
\hline Left ventricular diastolic pressure $(\mathrm{mmHg})$ & $22.7(23.01)$ & $27.8(10.56)$ & 0.047 \\
\hline Mean gradient & $20.8(11.64)$ & $18.6(11.10)$ & 0.68 \\
\hline
\end{tabular}

Note: M: Mean; SD: Standard Deviation, Mann Whitney test performed for left ventricular diastolic pressure. Systolic pulmonary arterial pressure and diastolic pulmonary arterial pressure data were not available for post-balloon aortic valvuloplasty.

Hemodynamic measurements were compared after and left ventricular diastolic pressure $(28 \pm 11 \mathrm{vs} 23 \pm 23 \mathrm{mmHg}$, BAV (Table 5). The reduction in mean gradient was similar $\mathrm{P}<0.047$ ). There were statistically significant greater mean between both groups, with $20.8 \pm 12 \mathrm{mmHg}$ in surviving patients values for those without mortality as compared to those and $18.6 \pm 11 \mathrm{mmHg}$ with in-hospital mortality. There were with mortality for systolic aortic blood pressure (144 \pm 24 vs statistically significant greater mean values for those with $114 \pm 28 \mathrm{mmHg}, \mathrm{P}<0.001$ ) and diastolic aortic blood pressure mortality as compared to those without mortality for mean $(50 \pm 8$ vs $63 \pm 14 \mathrm{mmHg}, \mathrm{P}<0.01)$. pulmonary arterial pressure ( $45 \pm 10$ vs $28 \pm 12 \mathrm{mmHg}, \mathrm{P}<0.01$ )

Table 6: Multivariate Logistic Regression Analyses for Mortality.

\begin{tabular}{|c|c|c|c|c|}
\hline Variable & $\begin{array}{c}\text { Model 1 } \\
\text { OR (95\% CI) }\end{array}$ & $\begin{array}{c}\text { Model } 2 \\
\text { OR (95\% CI) }\end{array}$ & $\begin{array}{c}\text { Model } 3 \\
\text { OR (95\% CI) }\end{array}$ & $\begin{array}{c}\text { Model } 4 \\
\text { OR (95\% CI) }\end{array}$ \\
\hline \multicolumn{5}{|c|}{ Lab Values } \\
\hline Blood urea nitrogen (mg/dL) & $1.0(0.99,1.08)$ & --- & --- & --- \\
\hline Creatinine $(\mathrm{mg} / \mathrm{dL})$ & $1.8(0.76,4.53)$ & --- & --- & --- \\
\hline \multicolumn{5}{|c|}{ Echocardiography Findings } \\
\hline $\begin{array}{l}\text { Estimated systolic pulmonary } \\
\text { artery pressure (mmHg) (pre) }\end{array}$ & --- & $1.1(0.98,1.14)$ & --- & --- \\
\hline Aortic insufficiency (post) & --- & $0.1(0.01,1.64)$ & --- & --- \\
\hline \multicolumn{5}{|c|}{ Pre-Balloon Aortic Valvuloplasty } \\
\hline $\begin{array}{l}\text { Systolic pulmonary arterial } \\
\text { pressure }(\mathrm{mmHg})\end{array}$ & --- & --- & $1.0(0.94,1.14)$ & --- \\
\hline $\begin{array}{l}\text { Diastolic pulmonary arterial } \\
\text { pressure }(\mathrm{mmHg})\end{array}$ & --- & --- & $1.1(0.90,1.28)$ & --- \\
\hline $\begin{array}{l}\text { Mean pulmonary arterial } \\
\text { pressure }(\mathrm{mmHg})\end{array}$ & --- & --- & --- & --- \\
\hline $\begin{array}{l}\text { Pulmonary capillary wedge } \\
\text { pressure }(\mathrm{mmHg})\end{array}$ & --- & --- & $1.0(0.91,1.19)$ & --- \\
\hline $\begin{array}{l}\text { Systolic aortic blood pressure } \\
(\mathrm{mmHg})\end{array}$ & --- & --- & $0.9(0.91,0.99)^{*}$ & --- \\
\hline \multicolumn{5}{|c|}{ Post-Balloon Aortic Valvuloplasty } \\
\hline $\begin{array}{l}\text { Mean pulmonary arterial } \\
\text { pressure }(\mathrm{mmHg})\end{array}$ & --- & --- & --- & $1.001(1.18,1.39)^{*}$ \\
\hline $\begin{array}{l}\text { Systolic aortic blood pressure } \\
(\mathrm{mmHg})\end{array}$ & --- & --- & --- & $1.0(0.85,1.09)$ \\
\hline $\begin{array}{l}\text { Diastolic aortic blood pressure } \\
(\mathrm{mmHg})\end{array}$ & --- & --- & --- & $0.8(0.59,1.07)$ \\
\hline $\begin{array}{l}\text { Left ventricular diastolic } \\
\text { pressure }(\mathrm{mm} \mathrm{Hg})\end{array}$ & --- & --- & --- & $1.1(0.96,1.20)$ \\
\hline
\end{tabular}

Note: OR: Odds Ratio; Cl: Confidence Interval. In Model 3, although mean pulmonary arterial pressure (mmHg) was entered into the analysis, the logistic regression analysis dropped it from the analysis due to redundancies. ${ }^{*}=p<0.05$ 
A multivariate logistic regression analysis for mortality is shown in Table 6. Model 3 for pre-balloon aortic valvuloplasty showed statistically significant decreased odds for increased systolic aortic blood pressure. Model 4 for post-balloon aortic valvuloplasty showed statistically significant increased odds for increased mean pulmonary arterial pressure. None of the variables for lab values in model 1 or echocardiography findings in model 2 was statistically significant.

\section{Discussion}

In this single center retrospective analysis of elderly patients deemed as high risk for SAVR/TAVI undergoing BAV for symptomatic severe calcific aortic stenosis, several variables were examined. Of the 68 patients who underwent the procedure, 10 deaths $(15 \%)$ occurred during the same hospital visit. This group has significantly higher rates of acute kidney injury prior to procedure, significantly elevated pulmonary artery pressures, and elevated left ventricular end diastolic pressures when compared to the survival group.

The two main landmark multi-center registries on BAV are the National Heart Lung and Blood Institute (NHLBI) and the Mansfield Scientific Aortic Valvuloplasty Registry $[15,16]$. The NHLBI registry contained 674 patients with a mean age of $78 \pm 9$ years and the Mansfield registry contained 492 patients with a mean age of $79 \pm 8$ years, both with severe aortic stenosis and deemed high risk for surgical intervention. The largest single center registry created at Mount Sinai Medical Center, NY contained 664 patients with a mean age of $83 \pm 9$ years. Patient's comorbidities were documented within each registry. NHLBI registry contained 276 (41\%) with HTN, 131 (20\%) with diabetes, 152 (23\%) with pulmonary disease, and 95 (14\%) with CKD. The Mansfield registry contained 81 (16.5\%) with HTN, 60 (12.2\%) with diabetes, 73 (14.8\%) with pulmonary disease, and $43(8.7 \%)$ with renal failure. The singlecenter Mount Sinai registry included 418 (63\%) with CKD, 126 (19\%) with pulmonary disease. Our 68 patient registry at Maimonides Medical Center, NY contained of the highest mean age of $85 \pm 8$ years with CAD in 35 (51\%), HTN in 37 (54\%), DM in $16(24 \%)$, Pulmonary disease in $4(6 \%)$, and CKD in $6(9 \%)$ of patients. When comorbidities were compared between the inhospital mortality vs survival groups in our study, no statistical significance was observed.

In Mount Sinai's registry, comparing gender-specific outcomes after BAV, in-hospital mortality was double in women compared to men $(8.1 \%$ vs $3.9 \%, \mathrm{P}=.02)$ [17]. Upon logistic regression model analysis, frailty and vascular complications were factors associated with increased mortality. Similarly, the surviving patients had an average body mass index (BMI) of 25.8 (range 20.9-36.7) as opposed to the in-hospital mortality group with a BMI of 20.2 (range 16.8-22.9). This reassures the inverse correlation between a lower BMI and increased frailty with increased in-hospital mortality.
When separating the procedures by decade duration, greatest deaths were present within the earliest decade at our institution. In the 1990s, of the 25 BAV's preformed, 6 (24\%) of patients died during the hospital stay. In the 2000s, all 23 BAV's were performed with no in-hospital mortality. After 2010, of the 20 BAV's preformed, $4(20 \%)$ of patients died during the hospital stay. Even though the number of deaths that occurred in patients who underwent the procedure in the 2010s was lower, these patients were found to have the most number of comorbidities, including hemodynamically unstable heart failure and acute kidney injury prior to valvuloplasty. In the study by Badheka et al. [17], the hospital mortality decreased by $23 \%$ from $11.5 \%$ in $1998-1999$ to $8.8 \%$ in $2009-2010$ (p $<.001$ ). They found significant predictors of in-hospital mortality with the presence with increasing numbers of comorbidities $(p=0.03)$, unstable patient $(p<.001)$, any complication $(p<.001)$, and weekend admission $(\mathrm{p}=0.008)$, whereas a higher operator volume was associated with a significant reduction in mortality $(\mathrm{p}=0.03)$. Patients who were admitted to hospitals with higher volumes along with high volume operators had a $51 \%$ reduced likelihood $(\mathrm{p}=0.05)$ of in hospital mortality when compared to hospitals with lower procedure volumes and less experienced operators [17]. Similarly, the acute and 30-day follow up results from the NHLBI Registry found in-hospital mortality to be greatest in patients with multi-organ failure due to poor cardiac output [18]. In a recent study of 25 patients who underwent BAV (mean age $72 \pm 11.4$ years, mean EuroScore of $10.4 \pm 11.7 \%$, mean logistic EuroScore of $23.5 \pm 23.6 \%$, \& mean Society of Thoracic Surgeons mortality risk score of $21.8 \pm 13.6 \%$ ) the in-hospital mortality was $20 \%(n=5)$ and occurred in those who underwent $\mathrm{BAV}$ in a setting of hemodynamically unstable heart failure [15].

On further review of the in-hospital mortality group occurring within the first decade at this institution, all were associated with vascular complications resulting in excessive bleeding. Similarly, other studies have reported this complication along with other serious outcomes including stroke, acute aortic regurgitation, and myocardial infarction in $10-20 \%$ or more of patients [18,19-22]. With improvements in vascular closure devices, patient outcomes have improved. An inpatient database collected from 1998 to 2010 consisting of 2127 percutaneous BAV's in patients greater than 60 years of age reported a complication rate of $28.9 \%$. The most common complications were respiratory related $(7.7 \%)$, cardiac related $(7.3 \%)$, and vascular related $(6.8 \%)$. The overall complication rate did not change significantly during the study period, however, the rate of vascular injury decreased to $2.9 \%$ during the end of the study period. Noteworthy, predictors of complications and poor outcomes included characteristics such as female gender, hemodynamic instability, and a greater number of comorbidities [22].

The post-BAV hemodynamic outcomes from both groups were similar; with the NHLBI study had a decrease in the 
aortic mean pressure gradient from $55 \pm 21$ to $29 \pm 13 \mathrm{mmHg}$, and the Mansfield Scientific from $60 \pm 23$ to $30 \pm 13 \mathrm{mmHg}$. The increase in aortic valve area was also similar with an increase from $0.5 \pm 2$ to $0.8 \pm 0.3 \mathrm{~cm} 2$ in the NHLBI registry and $0.5 \pm 0.18$ to $0.82 \pm 0.30 \mathrm{~cm} 2$ in the Mansfield Scientific registry. When compared to the registries mentioned above, our patient population was significantly older $(85 \pm 8$ years) with a greater overall reduction in aortic mean pressure gradient and greater increase in aortic valve area. This could be explained by marked improvements in BAV technique over the years. Specifically, the use of balloon catheters with smaller sheath sizes, the advent of vascular closure devices, and the use of rapid ventricular pacing have been showed to be associated with decreased procedural complications and improved outcomes. Also noteworthy, the patients who survived had multiple number of balloon inflations, however, this frequently resulted in a higher incidence of aortic insufficiency.

Currently, no method can accurately predict patient outcomes post-BAV. Various studies, including ours, have identified common characteristics associated with poor outcomes. Researchers at Mount Sinai Medical Center, NY, derived a risk score, the CRRAC (Critical status, Renal dysfunction, Right Atrial pressure, Cardiac Output) AV score, to identify patients at highrisk of 30-day mortality after BAV. 30-day survival was $72 \%$ in the highest quartile verses $94 \%$ in the lower two quartiles of the score. Compared to the additive and logistic EuroSCORE, the CRRAC-AV score demonstrated greater discrimination (AUC $=0.75$ vs 0.60 and 0.63 , respectively) [18,23-25].

In 2014, the American Heart Association/American College of Cardiology (AHA/ACC) guideline states that percutaneous balloon aortic valvotomy may be used as a bridge to surgical aortic valve replacement (AVR) or transcatheter AVR (TAVR) in selected patients with severe symptomatic calcific aortic stenosis [24]. BAV may also be considered as a palliative option in select patients when surgery and TAVR are not options in order to provide short-term symptomatic relief. European guidelines also recommend BAV as a bridge to SAVR to TAVI in unstable patients who are high risk for surgery or in patients with symptomatic severe AS who require urgent non-cardiac intervention. In patients initially deemed as poor candidates for SAVR/TAVR and successfully undergo BAV resulting in improved hemodynamics, it may be possible to bridge these patients to more permanent solutions such as SAVR/TAVR [25]. Similarly, $\mathrm{BAV}$ can be used to evaluate if a patient will benefit from valve replacement when other comorbidities exist such as severe pulmonary hypertension, severe lung disease, a poor ejection fraction, or frailty with a transient improvement [26-30]. Limited information regarding bridging patients to SAVR/TAVR with BAV currently exists and more information needs to be obtained, especially as individuals are living longer and calcific aortic stenosis being inevitable.

\section{Conclusion}

This study comprehensively evaluates trends for percutaneous aortic balloon valvuloplasty in one of the busiest community hospitals in a major city in the United States and demonstrates significant predictors of in-hospital mortality after percutaneous balloon aortic valvuloplasty. The initial enthusiasm of BAV as an alternative to SAVR in patients with calcific AS diminished as large registries showed its failure to alter the natural history aortic orifice narrowing and its associated procedural complications. The development in TAVR resurrected the use of BAV through its integral role in dilating the stenotic orifice for optimal prosthetic placement. It also reinforces that PBAV can be performed even in critically ill patients resulting in immediate symptomatic relief and hemodynamic improvement. Given the limitations observed with percutaneous balloon aortic valvuloplasty, this procedure is not a substitute for valve replacement in adults with calcific aortic valve disease; however, may provide potential in bridge patients initially deemed unsuitable to more definitive therapies.

\section{Limitations}

The authors acknowledge limitations of the procedure itself as well as this study on percutaneous balloon aortic valvuloplasty. In this single-center registry, results should be interpreted with caution in the general population. Data was retrospectively collected consisting of a small series of patients undergoing PBAV. Although a thorough review of the medical chart was preformed, not all values were documented. The failure to observe significant predictors of mortality other than pre-BAV increased systolic aortic blood pressure and postBAV increase in mean pulmonary artery pressure may indicate that the small sample size limited our capacity to thoroughly investigate these associations.

\section{References}

1. Yazdanyar A, Newman AB (2009) The burden of cardiovascular disease in the elderly: morbidity, mortality, and costs. Clin Geriatr Med 25(4): 563-577.

2. Osnabrugge RJ, Mylotte D, Head SJ, Van Mieghem NM, Nkomo VT, et al. (2013) Aortic Stenosis in the Elderly: Disease Prevalence and Number of Candidates for Transcatheter Aortic Valve Replacement: A MetaAnalysis and Modeling Study. J Am Coll Cardiol 62(11): 1002-1012.

3. Stewart RL, Chan KL (2009) Management of asymptomatic severe aortic stenosis. Curr Cardiol Rev 5(1): 29-35.

4. Otto CM, Bonow RO (2007) Valvular heart disease. In: Zipes DP, Libby P, Bonow RO, Braunwald E (Eds.), Braunwald's Heart Disease: A Textbook of Cardiovascular Medicine. $8^{\text {th }}$ (edn.), WB Saunders, St. Louis, Mo, USA 62: (1625-1634).

5. Varadarajan P, Kapoor N, Bansal RC, Pai RG (2006) Clinical profile and natural history of 453 nonsurgically managed patients with severe aortic stenosis. Ann Thoracic Surg 82(6): 2111-2115.

6. Jabbour RJ, Dick R, Walton AS (2008) Aortic balloon valvuloplastyreview and case series. Heart Lung Circ 17(Suppl 4): S73-S81. 
7. Ross J, Braunwald E (1968) Aortic stenosis. Circulation 38(1 Suppl): 61-67.

8. Rosenhek R, Binder T, Porenta G, Lang I, Christ G, et al. (2000) Predictors of outcome in severe, asymptomatic aortic stenosis. N Engl J Med 343(9): 611-617.

9. Smith CR, Leon MB, Mack MJ, Miller DC, Moses JW, et al. (2011) Transcatheter versus surgical aortic-valve replacement in high-risk patients. N Engl J Med 364(23): 2187-2198.

10. Leon MB, Smith CR, Mack M, Miller DC, Moses JW, et al. (2010) Transcatheter aortic-valve implantation for aortic stenosis in patients who cannot undergo surgery. N Engl J Med 363(17): 1597-1607.

11. Ben-Dor I, Pichard AD, Gonzalez MA, Weissman G, Li Y, et al. (2010) Correlates and causes of death in patients with severe symptomatic aortic stenosis who are not eligible to participate in a clinical trial of transcatheter aortic valve implantation. Circulation 122(11 suppl): S37-S42.

12. Ben-Dor I, Pichard AD, Satler LF, Goldstein SA, Syed AI, et al. (2010) Complications and outcome of balloon aortic valvuloplasty in high-risk or inoperable patients. JACC Cardiovasc Interv 3(11): 1150-1156.

13. Cribier A, Savin T, Saoudi N, Rocha P, Berland J, et al. (1986) Percutaneous transluminal valvuloplasty of acquired aortic stenosis in elderly patients: an alternative to valve replacement? Lancet 1(8472): 63-67.

14. Klein A, Lee K, Gera A, Ports TA, Michaels AD (2006) Long-term mortality, cause of death, and temporal trends in complications after percutaneous aortic balloon valvuloplasty for calcific aortic stenosis. Interv Cardiol 19(3): 269-275.

15. Bashore TM (1991) Percutaneous balloon aortic valvuloplasty. Acute and 30-day follow-up results in 674 patients from the NHLBI Balloon Valvuloplasty Registry. Circulation 84(6): 2383-2397.

16. Isner JM (1991) Mansfield Scientific Aortic Valvuloplasty Registry investigators. Acute catastrophic complications of balloon aortic valvuloplasty. J Am Coll Cardiol 17(6): 1436-1444.

17. Christodoulidis G, Yu J, Kini A, Dangas GD, Baber U, et al. (2015) Genderspecific outcomes after balloon aortic valvuloplasty: Inhospital and long-term outcomes. Am Heart J 170(1): 180-186.

18. Badheka AO, Patel NJ, Singh V, Shah N, Chothani A, et al. (2014) Percutaneous aortic balloon valvotomy in the United States: a 13-year perspective. Am J Med 127(8): 744-753.

19. Olasińska-Wiśniewska A, Grygier M, Lesiak M, Trojnarska 0 , Araszkiewicz A, et al. (2015) Balloon aortic valvuloplasty-ups and downs-do we face the procedure comeback? Kardiol Pol 74(3): 231236.

20. Nishimura RA, Holmes DR, Reeder GS (1990) Percutaneous balloon valvuloplasty. Mayo Clin Proc 65(2): 198-220.

21. Lieberman EB, Bashore TM, Hermiller JB, Wilson JS, Pieper KS, et al. (1995) Balloon aortic valvuloplasty in adults: failure of procedure to improve long-term survival. J Am Coll Cardiol 26(6): 1522-1528.

22. Naidu SS, Wong SC, Steingart RM (2007) Interventional therapies for heart failure in the elderly. Clin Geriatr Med 23(1): 155-178.

23. Elmariah S, Lubitz SA, Shah AM, Miller MA, Kaplish D, et al. (2011) A novel clinical prediction rule for 30-day mortality following balloon aortic valuloplasty: The CRRAC the AV score. Catheter Cardiovasc Interv 78(1): 112-118.

24. Costopoulos C, Sutaria N, Ariff B, Fertleman M, Malik I, et al. (2015) Balloon aortic valvuloplasty as a treatment option in the era of transcatheter aortic valve implantation. Expert Rev Cardiovasc Ther 13(5): 457-460.

25. Elmariah S, Arzamendi D, Palacios IF (2012) Balloon aortic valvuloplasty in the transcatheter aortic valve replacement era Interventional Cardiology Clinics 1(1): 129-137.

26. Eles GR, Khalil R, Lasorda D, Spotti I (2013) Balloon aortic valvuloplasty in elderly patients: a review and update. Interventional Cardiology 5(2): 213-219.

27. Nishimura RA, Otto CM, Bonow RO, Carabello BA, Erwin JP, et al (2014) 2014 AHA/ACC Guideline for the Management of Patients With Valvular Heart Disease: Executive Summary: A Report of the American College of Cardiology/American Heart Association Task Force on Practice Guidelines. Circulation 129(23): 2440-2492.

28. Saia F, Marrozzini C, Moretti C, Ciuca C, Taglieri N, et al. (2011) The role of percutaneous balloon aortic valvuloplasty as a bridge for transcatheter aortic valve implantation. EuroIntervention 7(6): 723729.

29. Pendyala LK, Ben Dor I, Waksman R (2012) Evolution of percutaneous balloon aortic valvuloplasty in the treatment of patients with aortic stenosis. Minerva Med 103(6): 415-429.

30. Cubeddu RJ, Jneid H, Don CW, Witzke CF, Cruz-Gonzalez I, et al. (2009) Retrograde versus antegrade percutaneous aortic balloon valvuloplasty: Immediate, short-and long-term outcome at 2 years. Catheter Cardiovasc Interv 74(2): 225-231.

\begin{tabular}{|l|}
\hline Your next submission with Juniper Publishers \\
will reach you the below assets \\
- Quality Editorial service \\
- Swift Peer Review \\
- Reprints availability \\
- E-prints Service \\
- Manuscript Podcast for convenient understanding \\
- Global attainment for your research \\
- Manuscript accessibility in different formats \\
( Pdf, E-pub, Full Text, Audio) \\
- Unceasing customer service \\
Track the below URL for one-step submission \\
https://juniperpublishers.com/online-submission.php \\
\hline
\end{tabular}

